\title{
Do desenvolvimento sustentável à economia verde: a constante e acelerada investida do capital sobre a natureza
}

\author{
From sustainable development to green economy: the constant and accelerated onslaught \\ of capital on nature
}

Maria Ceci Misoczky ${ }^{1}$

Steffen Böhm ${ }^{2}$

\begin{abstract}
Resumo
Informado por uma perspectiva teórica marxista, o propósito deste ensaio é refletir criticamente sobre a relação entre capital e natureza e, especificamente, sobre o 'processo Rio', que se iniciou em 1992 e continuou com a recente Conferência Rio+20. Neste processo constata-se uma evolução do discurso do desenvolvimento sustentável à economia verde relacionando-os a práticas fundamentalmente similares e contínuas que permitem ao capital cooptar conceitos inicialmente radicais, tais como sustentabilidade, de modo a incluí-los em sua lógica de acumulação. Neste ensaio discutimos uma variedade de autores para refletir criticamente sobre as tentativas recentes de organização do capital e seus contínuos avanços sobre a natureza, de modo a preservar o crescimento contínuo e contrarrestar a crise em que está imerso.
\end{abstract}

Palavras-chave: Desenvolvimento sustentável. Economia verde. Financeirização. Acumulação capitalista.

\begin{abstract}
Informed by a Marxist theoretical perspective, the aim of this essay is to critically reflect on the relationship between capital and nature and specifically the 'Rio process', which started in 1992 and continued with the recent Rio+20 conference. In this process we have seen a discursive evolution from sustainable development to green economy. We argue that these two terms nevertheless relate to fundamentally similar and continuous practices, enabling capital to coopt once radical concepts, such as sustainability, in order to include them in its logic of accumulation. In this essay we discuss a range of authors to critically reflect about capital's recent reorganization attempts and its continuous onslaught on nature, which aims at preserving its continuous growth, counteracting the crisis in which it is immersed.
\end{abstract}

Keywords: Sustainable development. Green economy. Financialization. Capitalist accumulation.

For the first time [...] nature becomes purely an object for humankind, purely a matter of utility; ceases to be recognized as a power for itself; and the theoretical discovery of its autonomous laws appears merely as a ruse so as to subject it under human needs, whether as an object of consumption or as a means of production.

Karl Marx, 1858

Artigo submetido em 30 de julho de 2012 e aceito para publicação em 09 de agosto de 2012.

${ }^{1}$ Doutora em Administração pela UFRGS; Professora associada da EA/PPGA/UFRGS. Endereço: Escola de Administração Pública Rua Washington Luiz, 855 - sala 427, CEP 90010-460, Porto Alegre - RS, Brasil. E-mail: mcaraujo@ea.ufrgs.br

${ }^{2}$ PhD em Business and Management pela Universidade de Warwick (UK); Professor em Management and Sustainability e Diretor do Essex Sustainability Institute da Universidade de Essex (UK). Endereço: Essex Business School, Sala 5NW.4.4, University of Essex, Wivenhoe Park, Colchester CO4 3SQ. E-mail: steffen@essex.ac.uk 
O propósito deste ensaio é realizar uma reflexão crítica, informada por uma perspectiva teórica marxista, sobre a evolução do desenvolvimento sustentável à era da economia verde, entendendo que se trata de um processo que meramente aprofunda fundamentos que já se encontravam presentes nos discursos desde a Eco92. Defendemos, portanto, que há uma linha de continuidade entre as proposições da Eco-92 e a consagração da "economia verde" na Rio+20. Como não poderia deixar de ser, em se tratando de uma reflexão crítica (MISOCZKY, MORAES e FLORES, 2009), ela se encontra situada na denúncia contra a investida do capital sobre a natureza, em sua estratégia para manter o crescimento contínuo e contrarrestar a crise na qual se encontra imerso.

Os autores e textos com os quais dialogamos são de dois tipos: alguns são tomados pelas contribuições críticas que vêm aportando ao tema ao longo das últimas décadas; outros são tomados como ilustração do processo sobre o qual refletimos. Em nenhum dos casos, é preciso deixar claro, trata-se de uma revisão exaustiva ou que segue critérios bibliométricos ou de qualquer outro tipo.

Como ainda temos dificuldades em lidar com a natureza do ensaio no campo disciplinar da Administração, recorremos, neste início de texto, aos valiosos esclarecimentos produzidos por Meneghetti (2011) sobre esse tema.

Na produção de um ensaio, não ocorre o "aprisionamento formal do ensaísta com o objeto empírico", o que lhe permite "refletir em todas as direções" e "aventurar-se na compreensão do objeto por associações ou analogias, sem, contudo, render-se ao formalismo da técnica científica tradicional" (MENEGHETTI, 2011, p. 327).

O ensaio não requer um sistema ou modelo específico, pois seu princípio está nas reflexões em relação aos próprios sistemas ou modelos. Permite a busca por novos enfoques e interação permanente com os próprios princípios da forma. No ensaio, busca-se a construção da forma adequada, mesmo que esta não exista a princípio. Nele, o objeto exerce primazia, mas a subjetividade do ensaísta está permanentemente em interação com ele (MENEGHETTI, 2011, p. 323).

$[\ldots]$

O ensaio é um meio para quem o escreve, assim como deve ser para quem o lê. No ensaio, o empírico já está apreendido pela consciência do ensaísta, e este reflete criticamente sobre o objeto. [...] O caráter do objeto refletido pelo ensaísta está associado à capacidade de estabelecer relações diversificadas entre o ensaísta, o objeto apreendido e outros objetos que possam relacionar-se aos dois primeiros (MENEGHETTI, 2011, p. 326).

$[\ldots]$

No ensaio, não é preciso uma conclusão no sentido tradicional; cada parte é uma conclusão por si mesma. No desenvolvimento do ensaio, são geradas as próprias conclusões para as reflexões anunciadas inicialmente em forma de questionamentos (MENEGHETTI, 2011, p. 330).

Feitos esses esclarecimentos inicias vamos, então, iniciar nossa reflexão sobre a evolução do desenvolvimento sustentável, entendido como a investida encoberta do capital sobre a natureza, à economia verde, entendida como a investida radical e aberta do capital sobre a natureza, tomando como marcos as Conferências Eco-92 e Rio+20.

Para começar, precisamos reconhecer que a criação de mercadorias ambientais não é nenhuma novidade. Sua origem remonta, pelo menos, aos anos 1970, década em que se disseminou a preocupação com os limites da abordagem instrumentalista, que tratava a natureza como fonte de recursos e depósito de restos. Parte desse processo se relaciona com a emergência do movimento ambientalista. A resposta do capital foi, como indica 
Bakker (2010, p. 726), um redirecionamento "das estratégias intensivas de acumulação para a comodificação de novos tipos de socionaturezas e para a conversão de externalidades ambientais em fontes de lucro, em articulação com bem estabelecidas estratégias de arranjos ecológicos". Simultaneamente, "a produção da natureza neoliberal se tornou um projeto global, mediado pelas organizações financeiras internacionais". Smith (2007) também indica que, contraditoriamente, a criação dessas novas mercadorias ambientais deve sua existência ao sucesso do movimento ambiental dos anos 1960 e 1970.

Em um texto anterior, Smith (1984, p. 97) havia cunhado a expressão "inscrição do capital na paisagem" para se referir aos modos como o capitalismo impactava a natureza. Se, anteriormente, a apropriação de bens naturais para fins econômicos se restringia ao extrativismo e à produção agrícola, a nova geração de mercadorias tem diferentes características:

Estas mercadorias são simultaneamente retiradas (em termos de valor de troca) de relações sócio-naturais pré-existentes e como parte de sua produção são reinseridas ou permanecem inseridas na natureza socializada - quanto mais "natural", melhor. O capitalismo verde pode ser considerado como um meio de suavizar os impactos ambientais da exploração capitalista da natureza, ou criticado como um mero portfólio ambiental para a exploração sustentada. Seja qual for a verdade sobre estas proposições, o significado do capitalismo verde é muito mais profundo. Ele tem se tornando nada menos que a principal estratégia para a mercantilização e financeirização da natureza, intensificando de modo radical a penetração do capital sobre a natureza (SMITH, 2007, p. 20).

James O'Connor, escrevendo em 1994, já reconhecia que a natureza precisava ser capitalizada e o capital ecologizado de novos modos. Nessa fase ecológica do capitalismo, o capital é tomado como medida da degradação ambiental que ele mesmo produz. Acabamos, assim, presos em uma espécie de armadilha tautológica. Escrevendo especificamente sobre a Eco-92, o autor registra que, se o objetivo formal era "salvar o planeta - salvar a herança natural e cultural, a diversidade genética, estilos de vida vernaculares etc." -, o resultado, sob a retórica da sustentabilidade, foi um boom "do próprio projeto do capital para ampliar sua reprodução": quando "o capital é natureza e a natureza é capital, e os termos se tornam virtualmente intercambiáveis", a reprodução do capital se torna sinônimo de salvar a natureza e o planeta como um todo, que é nosso capital, precisa ser sustentavelmente gerenciável (O'CONNOR, J., 1994, p. 132133). Martin O'Connor (1994, p. 158) já advertia que era preciso prestar atenção à "natureza capitalista", uma natureza reconstituída biológica e fisicamente, política e ideologicamente, pelo capital "à sua própria imagem e semelhança". Estávamos, enfim, entrando em um novo mundo, um mundo com paisagens ecológicas, culturais e regulatórias novas.

Naquele contexto, como é de amplo conhecimento, a Assembleia Geral das Nações Unidas decidiu, em 1983, criar a World Comission on Environment and Development (WCED) para analisar a situação ambiental do planeta em relação às metas de desenvolvimento. Suas recomendações para ação resultaram no documento Our Common Future, conhecido como o Relatório Brundtland (WCED, 1987). Nele estavam contidas as bases que orientaram os debates e negociações ocorridas na Conferência Internacional sobre Meio Ambiente e Desenvolvimento Sustentável (Eco-92), realizada no Rio de Janeiro em 1992.

No Relatório Brundtland (WCED, 1987) se encontra o argumento central de que a melhor maneira de responder aos desafios colocados pela destruição ambiental e pela pobreza era com mais crescimento. Diante das críticas crescentes contra a ideia do crescimento ilimitado em um planeta limitado, foi produzido, de acordo com Lander (2011, p. 1), um ato de "extraordinário malabarismo conceitual" na concepção da expressão "desenvolvimento sustentável". Beckerman (1994), na mesma direção, indica que o conceito mistura as características técnicas de um caminho particular de desenvolvimento com uma injunção moral que o define como a escolha ótima para toda e qualquer sociedade. Essa ideia se tornou, desde então, a abordagem conceitual dominante para respostas aos problemas ambientais e capturou a imaginação da opinião mundial (BERNSTEIN, 2002). Unmüßig, Sachs e Fatheuer (2012) recordam que o conceito de desenvolvimento como crescimento nunca foi, de fato, questionado. Para os autores, a ambiguidade do termo desenvolvimento encobriu a inexistência de conexões automáticas e consistentes com a proteção ambiental. 
Essa ambiguidade se expressa nos acordos produzidos no Rio de Janeiro: por um lado, a convocação para uma virada ecológica e, por outro, a subscrição da necessidade de crescimento econômico, livre-comércio, privatização e desregulamentação.

Na análise de Biersteker (1992), a Eco-92 institucionalizou a concepção de que a liberalização do comércio e das finanças é consistente e, mesmo, necessária, para a proteção ambiental, sendo compatível com a meta do crescimento econômico dito sustentável. Assim, o Relatório da Eco-92 não apenas incorporou, mas catalisou a nova ortodoxia econômica que vinha se disseminando pelos países do Sul a partir das agências internacionais de financiamento e apoio ao desenvolvimento. Lembremos que estávamos no auge do Consenso de Washington.

Em 1994, Chatterjee e Finger já indicavam que a Eco-92 havia sido uma realização para os grandes negócios. Nela foi consolidado o papel das corporações multinacionais como agentes da mudança ambiental. Para os autores, esse não foi um evento isolado, mas a culminação de anos de evolução na ideologia do desenvolvimento e do esforço para adaptar a equação crescimento e industrialização com o desafio colocado pelo ambientalismo. O documento final e a Agenda 21 não incluíram qualquer tipo de regulação para limitar a ação das corporações ou o livre-comércio, nem para reduzir os recursos consumidos pelos países do Norte. Em vez disso, reiterou o modelo ocidental de desenvolvimento ao propor que as soluções deveriam advir de inovações tecnológicas, da disseminação de informações e treinamentos, sempre a partir do paradigma da modernização e da difusão de valores e modelos dos países centrais ocidentais industrializados.

Bernstein (2002) valoriza o legado das decisões tomadas na Eco-92, indicando como aquelas ideias influenciaram os mais importantes acordos ambientais internacionais, como os tratados sobre mudança climática e da biodiversidade, bem como as políticas e programas de organizações ambientais e do desenvolvimento que vão das Nações Unidas ao Banco Mundial e incluem o modo como organizações como a OMC tentam responder às demandas para acomodar a relação entre desenvolvimento e ambiente. Além disso, as ONGs e muitos países orientaram suas propostas para ação sobre essa base normativa. Bernstein (2002) denomina esse legado de compromissos do ambientalismo liberal, referindo-se ao conjunto de normas e recomendações que aliam proteção ambiental e manutenção da ordem econômica liberal. Em um artigo anterior, Bernstein (2002) havia explicado, com base nas proposições teóricas da Florini (1993) e March e Olsen (1998) sobre adequação social, porque normas associadas ao ambientalismo liberal se tornaram institucionalizadas, enquanto outras foram deixadas de lado. $\mathrm{O}$ argumento defendido, em uma abordagem denominada socioevolucionista, é que novas ideias precisam de alguma adequação às estruturas sociais internacionais existentes, ou ao conjunto mais amplo de normas institucionalizadas já aceitas como legítimas bases de governança no sistema internacional. Aplicando esse referencial, Bernstein (2002) conclui que o ambientalismo liberal resultou da sua capacidade de prover determinadas respostas aos problemas ambientais globais que eram consistentes com a lógica, em vigência, da governança privada e do predomínio e expansão dos mecanismos de mercado, ao mesmo tempo que propõe a convivência de valores como eficiência, crescimento econômico, e liberdade corporativa com a proteção ambiental. Assim, uma expressão que tinha, para alguns, na década de 1980, um caráter emancipatório e crítico do sistema terminou por se institucionalizar em associação a opções de reforma aceitáveis para o sistema.

Dizendo de modo simples: se, em meados do século XX, os princípios do mercado eram, frequentemente, considerados como em oposição à proteção e conservação ambiental, no final do século eles foram reconciliados com o crescimento econômico e se tornaram parte central da política ambiental dominante sob o emblema do desenvolvimento sustentável. A neoliberalização da sócio-natureza precisa ser, então, compreendida como sendo, simultaneamente, um modo disciplinar de regulação e um regime emergente de acumulação que redefine os constituintes sócio-naturais (BAKKER, 2010, p. 726-727).

O contrabando da agenda dos negócios para dentro das Nações Unidas foi ficando cada vez mais evidente ao longo da década. Bruno e Karliner (2002a) denunciavam esse fato em relação à Rio+10, ocorrida em 
Johannesburg. Os autores afirmam que a nova ordem que teria se originado na Eco-92 era idêntica à velha ordem. Para chegar a essa conclusão revisaram os processos da United Nations Conference on Environment and Development, detalhando suas origens, contexto, principais agentes envolvidos e resultados. Em outra publicação, Bruno e Karliner (2002b) evidenciam, através da análise de 18 casos, como as corporações transnacionais cooptaram a retórica da responsabilidade social e ambiental, com apoio da Organização Mundial do Comércio (OMC) e das Nações Unidas. Desprezando uma das definições-chave da Eco-92, segundo a qual os padrões elevados de consumo e produção de alguns países não poderiam ser copiados em escola global, a OMC, criada em janeiro de 1995, constituiu-se em organização de apoio à corrida pela exploração dos recursos naturais necessários para a aceleração de um novo ciclo de acumulação, como Hartwick e Peet (2003) evidenciam.

Hoedeman (2012, p. 3) registra que a Rio+10 foi descrita pelo então presidente do United Nations Environmental Programme (UNEP) como a "maior feira de negócios do mundo". Mais de 100 CEOs das maiores corporações e cerca de outros 600 delegados de empresas compareceram, disseminando a mensagem de que os negócios estariam agindo voluntariamente para resolver desafios ambientais e que regulações governamentais não eram necessárias. O impacto de sua estratégia foi bastante efetivo, já que a Rio+10 resultou na ênfase em parcerias entre corporações e ONG, entre corporações e governos, entre corporações e agências das Nações Unidas. Além disso, expôs o fato de que a relação entre essa organização e os grandes negócios havia mudado, passando de um distanciamento crítico à parcerias e crescente cooptação.

Antes que o leitor nos acuse de ignorar a existência de diferentes definições de desenvolvimento sustentável, revisamos sua origem e as discussões sobre a ambiguidade nele presente.

O conceito de desenvolvimento sustentável surgiu com o nome de ecodesenvolvimento nos anos 1970. Foi fruto do esforço para encontrar uma terceira via opcional àquelas que opunham, de um lado, desenvolvimentistas e, de outro, defensores do crescimento zero. Para estes últimos, chamados de 'zeristas' ou (pejorativamente) 'neomalthusianos', os limites ambientais levariam a catástrofes se o crescimento não cessasse. A controvérsia opondo desenvolvimentistas e 'zeristas' iniciou-se com a publicação do relatório preparado pelo casal Meadows, do MIT, sob os auspícios do chamado Clube de Roma, sobre limites ambientais ao crescimento econômico [...]. Num primeiro momento, as reações de todas as correntes à conclusão do Relatório do Clube de Roma foram de rejeição. Para os economistas do mainstream porque, em primeiro lugar, havia razões teóricas para rejeitar a ideia de que os recursos naturais pudessem representar um limite absoluto ao crescimento econômico; em segundo lugar, pelas consequências socioeconômicas e políticas do crescimento zero tanto para países pobres como para países ricos (ROMEIRO, 2012, p. 68).

Nas Conferências das Nações Unidas sobre esse tema, ocorridas na década de 1970, houve uma conciliação com o apoio dos ecodesenvolvimentistas, "no sentido não somente de defender a necessidade do crescimento econômico para os países pobres, mas de considerar a própria pobreza como uma das causas fundamentais dos problemas ambientais desses países" (ROMEIRO, 2012, p. 89).

Gladwin, Kennelly e Krause (1995) sintetizaram os desdobramentos conceituais produzidos nos primeiros anos após o lançamento do Relatório Brundtland (WCED, 1987), identificando definições alternativas de desenvolvimento sustentável, economia sustentáveis e sociedades sustentáveis, e indicando que esses construtos estão infundidos de múltiplos objetivos e ingredientes. Em consequência, para os autores, o destino do tema do desenvolvimento sustentável era permanecer confuso, elusivo, contestável e ideologicamente controverso. Entendemos que essa característica, entre outros aspectos, contribuiu para sua absorção pela Realpolitik.

James O'Connor (1994, p. 152) também chama a atenção para a ambiguidade contida no termo "sustentável": 
Existem poucas expressões tão ambíguas quanto "capitalismo sustentável” e seus conceitos irmãos como "agricultura sustentável", "uso sustentável de recursos e energia”, e "desenvolvimento sustentável". Esta ambiguidade se expressa nos mais importantes discursos sobre economia e ambiente - relatórios das Nações Unidas e de governos, pesquisa acadêmica, jornalismo popular, pensamento político verde. Precisamente esta obscuridade leva tantas pessoas a falar e escrever sobre "sustentabilidade": a palavra pode ser usada para significar qualquer coisa que se queira dizer, o que é parte do seu apelo.

Shiva (1992) identifica diferentes e contraditórios significados do termo sustentabilidade quando este tem como referência a natureza ou o mercado. Na natureza, sustentabilidade se refere a processos regenerativos e de subserviência às leis da natureza em combinação com o sustento e sobrevivência de populações nativas. No mercado, sustentabilidade se refere a assegurar o suprimento de matéria-prima, o fluxo de mercadorias, a acumulação de riqueza e o retorno do investimento. Defendemos que o significado de sustentabilidade institucionalizado ao longo das décadas pós-Eco-92 foi o do mercado, e que a ambiguidade que acompanha a expressão tem sido funcional à legitimação e ao encobrimento da investida do capital sobre a natureza.

Redclift (2006) destaca que termo desenvolvimento sustentável é um oximoro, tendo instigado diversas interpretações para articular desenvolvimento e sustentabilidade. Em primeiro lugar, é preciso destacar que o esforço de integração dos temas ambiente e desenvolvimento é uma expressão da tradição modernizadora, enfatizando a necessidade de viver dentro de limites ecológicos, mas, ao tempo, retendo uma visão essencialmente otimista da ideia de progresso (REDCLIFT, 1993). Em segundo lugar, trata-se de reconhecer que esse tema ganhou legitimidade em um momento de abandono do paradigma keynesiano e "ascensão das certezas neoliberais das décadas de 1980 e 1990":

A imposição da economia de mercado no ambiente global teve resultados paradigmáticos e práticos. O foco nas escolhas dos indivíduos e grandes grupos sociais, expressas através de preferências no mercado, levou ao crescimento das disparidades entre demandas sociais e políticas, e a alocações através do mercado. A economia política internacional, na ortodoxia neoliberal significou que "ajustes" econômicos deveriam ser feitos com pouca, ou nenhuma consideração social. A proteção ambiental, e os valores das diferentes culturas com relação aos seus ambientes, passaram a ser formalmente expressos em termos de mercado e de preços (REDCLIFT, 2006, p. 81).

O fato é que o conceito foi, política e ideologicamente, extremamente efetivo. Em parte, ele parecia responder às críticas ao modelo de desenvolvimento quando, de fato, o reforçava:

Ele funcionou como um calmante, ao criar a ilusão de que medidas efetivas estavam sendo tomadas para responder à crise diagnosticada. Ao não questionar a lógica da acumulação capitalista e o modelo de sociedade industrial que eram as causas fundamentais da destruição ambiental, proveu uma nova legitimidade à globalização neoliberal que começou a se apresentar como sustentável, apesar da sua dinâmica esmagadoramente devastadora (LANDER, 2011, p. 3).

É preciso, ainda, reconhecer a relação das proposições sobre desenvolvimento sustentável com a abordagem da modernização ecológica. Essa abordagem vinha se desenvolvendo desde os anos 1980 na Alemanha, principalmente. O primeiro artigo sobre esse tema, em língua inglesa, foi publicado apenas em 1992, sendo de autoria de Spaargaren e Mol. Nele, os autores contextualizam suas proposições no cenário da sociedade pós-industrial e afirmam que a melhor opção para escapar da crise ecológica no mundo desenvolvido seria através do contínuo desenvolvimento industrial, ou seja, a melhor solução para os problemas ambientais reside no avanço tecnológico e na expansão da produção industrial. Os autores defendem, ainda, que as melhorias ambientais são economicamente viáveis, já que agentes empreendedores e mercados dinâmicos 
desempenhariam um papel central na concretização de mudanças ecológicas necessárias. Além disso, em um contexto de expectativa de continuado crescimento econômico, a modernização ecológica confere aos atores políticos, em diferentes coalizões, a tarefa de tornar a proteção ambiental viável. Ou seja, a abordagem advoga a possibilidade de reformar o capitalismo através de mecanismos de regulação e da inovação tecnológica, propiciando soluções que sejam, simultaneamente, ambientas e econômicas (SPAARGAREN e MOL, 1992; MOL, 2002; 2003; VLACHOU 2004). Nas palavras de Mol (1995, p. 42), "o único caminho para sair da crise ecológica é avançar mais ainda no processo de modernização". Hajer (1995), de modo sintético, descreve a modernização ecológica como um processo que emprega uma abordagem regulatória baseada na suposição de que os problemas ecológicos podem ser resolvidos em compatibilidade com o contínuo crescimento econômico.

A abordagem da modernização ecológica foi criticada por autores que indicaram a impossibilidade lógica de um "capitalismo sustentável", sugerindo que a constante e crescente acumulação é incompatível com o metabolismo da natureza. Esse foi o caso, entre outros, de Foster (1992). Uma das críticas mais difundidas foi a de Martin O'Connor (1991; 1994), ainda que esse autor, diferente de Foster (1992), fique restrito à dimensão econômica e conteste a modernização ecológica nos termos da segunda contradição do capitalismo (O’CONNOR, M., 1994), segundo a qual a depleção de recursos naturais aumentaria os custos de produção para o capital e contribuiria para o surgimento de crises.

Apesar de críticas como essa, a investida do capital sobre a natureza, sob a égide do desenvolvimento sustentável continuou, contando com o apoio da denominada gestão verde ou ambiental que, simultaneamente, se orienta para a criação de novos produtos nos circuitos culturais do capitalismo (THRIFT, 2005), como consultorias e publicações, e para o encobrimento de práticas predatórias sob o marketing da responsabilidade ambiental; além de contribuir para a disseminação da linguagem dos negócios para o tratamento de temas ambientais.

Haden, Oyler e Humphreys (2009) definem a gestão verde como um processo organizacional amplo que aplica a inovação para atingir a sustentabilidade, redução de perdas, responsabilidade social e vantagens competitivas através da contínua aprendizagem e desenvolvimento, bem como pela adoção de metas e estratégias ambientais que estejam totalmente integradas com as metas e estratégias da organização. Marcus e Fremeth (2009) consideram que o entusiasmo com a chamada gestão verde deriva da expectativa de que os gestores e as organizações possam conduzir seus negócios para proteger o ambiente. Isso ocorreria quando a firma é capaz de adquirir competências verdes.

Cohen, Smith e Mitchell (2008) defendem que os objetivos sociais, ambientais e dos negócios podem e devem ser buscados de modo simultâneo. A sustentabilidade é, portanto, definida, como a integração exitosa desses múltiplos objetivos. Para atingi-la, os negócios teriam um papel positivo como agentes de mudança global tanto para promover o bem-estar dos pobres (PRAHALAD, 2005) quanto para desenvolver inovações tecnológicas (HART, 1997). Nas palavras de Hart (2005, p. 3), "as corporações são as únicas entidades no mundo contemporâneo com a tecnologia, os recursos, a capacidade e alcance global" necessários para resolver, ao mesmo tempo, os problemas sociais e ambientais. Siegel (2009), por sua vez, defende que as firmas devem adotar a prática da gestão verde apenas se essas atividades complementam o negócio da organização e as estratégicas corporativas, se aumentam a lucratividade e os ganhos dos acionistas. Savitz (2007) apresenta, em seu livro sobre a empresa sustentável, uma análise sobre a ascensão da sustentabilidade no mundo dos negócios como argumento para uma série de prescrições sobre como a sustentabilidade pode ajudar a empresa a obter sucesso financeiro. Em 2007, a Harvard Business Review publicou um número especial sobre mudança climática. Nas contribuições para esse número, como nos artigos de Bakhshi e Krajesk (2007), Lash e Wellington (2007), Porter e Reinhardt (2007) e Schwartz (2007), fica clara a defesa da relação entre aspectos ambientais e estratégia corporativa, bem como a necessidade do desenvolvimento de novos instrumentos para potencializar o lucro que daí pode advir.

Em nosso contexto, por exemplo, Sanches (2000), defendia que as empresas industriais que quisessem manter-se competitivas ou, mesmo, sobreviver e ajustar-se a um ambiente de negócios turbulento e 
imprevisível deveriam, cada vez mais, levar em consideração as questões ambientais e adotar novas posturas, em processos de renovação contínua, no modo de operar seus negócios e as organizações através de mecanismos de autorregulação e de uma gestão ambiental proativa. Em outra direção, Crubellate e Vasconcelos (2003, p. 91) sugeriam, a partir da teoria dos sistemas sociais, que "a gestão ambiental possui uma função muito mais relacionada às necessidades de legitimação envolvidas com a exploração e degradação ambiental do que com a efetiva conscientização e proteção ecológica". Finalmente, para concluir esta breve ilustração sobre o tema em nosso contexto de práticas, registramos o estudo realizado por Silva, Reis e Amâncio (2011), que teve como objetivo compreender os significados atribuídos à sustentabilidade e como eles se relacionam com os paradigmas ambientais compartilhados. Realizando uma análise de conteúdo, os autores concluem que a sustentabilidade está relacionada com conceitos como os de crescimento, rentabilidade, liderança e boas práticas de governança nas organizações, tendo como tema central o relato dos resultados financeiros das organizações.

Milne, Kearins e Walton (2006) discutem as publicações nas áreas da gestão, estudos organizacionais e contabilidade sobre sustentabilidade e identificam a existência de duas vertentes de pensamento: a dominante segue uma linha funcionalista e privilegia a captura gerencial do conceito de sustentabilidade através de melhoras incrementais, estando subsumida pela teoria da modernização ecológica (HAJER, 1995); a mais crítica sugere que são necessárias mudanças fundamentais nos modelos atuais de organizar. A partir desse cenário, os autores argumentam que a metáfora da viagem, presente em vários relatórios e anúncios corporativos, bem como em comentários de associações profissionais e de negócios, evoca imagens de adaptação, aprendizagem e progresso, de um movimento para fora das práticas usuais dos negócios. A metáfora da viagem, no entanto, "mascara o tema da direção na qual os negócios estão, ou supõem estar, se movendo", ou seja, ao construir a sustentabilidade como uma viagem, os comentadores de negócios e outros perpetradores da retórica corporativa "aparentam estar seriamente engajados com elementos do discurso sobre desenvolvimento sustentável e sustentabilidade, mas ao mesmo tempo e paradoxalmente reforçam as práticas usuais dos negócios" (MILNE, KEARINS e WALTON, 2006, p. 825).

Fizemos esses registros porque entendemos que é precisamente através da disseminação dos discursos sobre sustentabilidade no mundo dos negócios, bem como através da difusão da dita gestão verde/ambiental nos circuitos culturais e empresariais, que a relação entre proteção da natureza e mercado vem se naturalizando. No entanto, essa é apenas a parte aparente e mais palatável da comodificação da natureza. A parte menos evidente é a que interessa para a aceleração do ciclo de acumulação do capital: a financeirização da natureza.

Smith (2007, p. 24) registra essa nova fronteira de expansão: "A emergência de novos mercados de commodities ecológicas, mitigação contabilizável, e derivativos ambientais". Na definição de Foster e McChesney (2009), financeirização é o processo através do qual as finanças se tornam dominantes sobre outras atividades da economia, tornando-se o principal motor de crescimento e expansão e gerando acumulação mesmo quando outras áreas econômicas estão estagnadas.

Para tratar desse tema é indispensável recorrer às proposições de David Harvey. De modo a "produzir sentido para as diversas, particulares e frequentemente idiossincráticas variações geográficas em relação ao processo mais geral de acumulação do capital, lutas sociais e transformação ambiental”, Harvey (2006, p. 78) evita a homogeneização da categoria natureza e propõe que a acumulação do capital opera através de processos ecossistêmicos, remodelando-os em localizações específicas. A ênfase na rede da vida socioecológica é interconectada com outras três dimensões em seu trabalho: acumulação por espoliação; o caráter de tendências da acumulação do capital no espaço tempo; e as lutas de classe, políticas e sociais que ocorrem em uma variedade de escalas geográficas. Para os fins deste ensaio, interessa-nos aprofundar a noção de acumulação por espoliação, elaborada por Harvey (2003) para dar conta dos mecanismos implementados durante a fase neoliberal do capitalismo para realizar a transferência de ativos e a redistribuição da riqueza e renda tanto das massas da população para as classes altas quanto dos países vulneráveis para os ricos. Para esse autor o neoliberalismo é definido como a "financeirização de tudo e a relocalização do poder de acumulação do capital dos proprietários para as instituições financeiras às expensas de outras frações do capital" (HARVEY, 2006, p. 22). 
As formas contemporâneas de acumulação incluem, então, práticas necessárias para superar as recorrentes crises de superacumulação, tais como: a comodificação da terra e a remoção forçada de grupos populacionais; a conversão de várias formas de direito de propriedade; a supressão de direitos sobre os bens comuns; a comodificação da força de trabalho e a supressão de formas alternativas de produção e consumo; processos coloniais, neocoloniais e imperiais de apropriação de ativos; o comércio de escravos que continua particularmente na indústria do sexo e no uso clandestino de trabalho imigrante; e a financeirização (HARVEY, 2006).

O referencial de Harvey serve, aqui, como uma ponte para a experimentação mais organizada de financeirização da natureza: o mercado de créditos de carbono. Ainda que a ideia de estabelecer mecanismos de mercado sobre as emissões já tivesse pelo menos três décadas de existência, o Protocolo de Kyoto, de 1997 (um dos desdobramentos da Eco-92), é certamente o marco para a sua concretização. O fundamento para sua proposição foi de que apenas mecanismos de mercado levariam à redução das emissões de modo eficiente e custo-efetivo - o máximo de redução de emissão ao menor custo possível (TIETENBERG, 2006). Desde então, o mercado de compensações se expandiu enormemente. De acordo com dados recentes, mais de 2.600 projetos de Clean Development Mechanism (CDM) estavam em análise em 2011, dos quais 3.146 já registrados e com a expectativa de produzir mais de 2 bilhões de Unidades Certificadas de Redução de Emissão em 2012 (UNFCC, 2011). O mercado voluntário de compensações, por sua vez, duplicou de tamanho apenas em 2008, quando valia cerca de US\$ 700 milhões (US DEPARTMENT OF ENERGY, 2011a; 2011b). As compensações de carbono estão projetadas para constituir uma indústria bilionária nos próximos anos, segundo a Bloomberg New Energy Finance (2010), por exemplo. De acordo com Sullivan (2011, p. 10), a proliferação do comércio de produtos de carbono naturaliza a ideia de "investimentos na nova fronteira da conservação". Assim, "a possibilidade de usar trocas no mercado para compensar danos ambientais em uma localização através de investimentos, em alguma medida de conservação ambiental ou de restauração, em outra localização é agora um aspecto da governança ambiental global”.

A financeirização é central nesse processo, bem como no capitalismo neoliberal, como já vimos na definição de Harvey (2006). Newell (2011, p. 3) não apenas reconhece essa centralidade, como defende que o poder do setor financeiro é fundamental para que se compreenda "a popularidade dos mercados de carbono, já que os financiadores são os principais beneficiários desta concepção política particular". Em vez de lamentar ou criticar essa financeirização, como Lohmann (2009), por exemplo, Newell e Paterson (2010) a veem como um aspecto necessário para o desenvolvimento de um capitalismo climático que, na sua concepção, é a nossa melhor esperança para descarbonizar a economia. Para os autores (NEWELL e PATERSON, 2009, p. 89), o setor financeiro, "apesar do seu caráter problemático", é essencial para as estratégicas de descarbonização. Eventuais problemas poderiam ser resolvidos através de "formas públicas e privadas de regulação, de práticas sociais e de coalizões". Essa governança do capitalismo climático poderia ser feita de modo adequado através do envolvimento de uma variedade de atores do mercado, do Estado e da sociedade civil. Portanto, de acordo com esses autores, a solução reside na mobilização de influência de poderosas frações do capital como meio para viabilizar estratégias que sejam compatíveis com a meta da descarbonização, e no uso do poder de Estado para dirigir investimentos, assegurando que os preços de carbono sejam estáveis e criem incentivos aos produtores, consumidores e investidores. O que eles têm em mente é uma espécie de "keynesianismo climático" (NEWELL e PATERSON, 2010, p. 186), criando um poderoso bloco capitalista que tem a descarbonização da economia como um núcleo da estratégia de acumulação e legitimação.

Retornando a Harvey, registramos que os mercados de carbono tem sido um dos exemplos de acumulação por espoliação, já que incluem a privatização, comodificação e financeirização (BUMPUS e LIVERMANN, 2008), além de ter como consequência efeitos negativos concretos sobre comunidades locais que se encontram próximas a grandes plantas industriais que se beneficiam da venda de créditos de carbono, como as diversas contribuições organizadas por Böhm e Dabhi (2009) mostram.

Ainda sobre a financeirização, escreve Moore (2010) que a penetração das finanças na vida cotidiana, e sobre tudo na reprodução da natureza extra-humana é um aspecto-chave do capitalismo na sua versão neoliberal. 
Antes de continuar nesse raciocínio, é preciso esclarecer a concepção desse autor sobre a relação entre capital e natureza, que é bastante original.

Moore (2011a, p. 115) define o capitalismo como uma ecologia-mundo que vem se desenvolvendo nos últimos séculos através de uma sucessão de crises e do subsequente estabelecimento de novos modos de acumulação e arranjos ecológicos globais. Ou seja, "o capitalismo não se desenvolve sobre a natureza, ele emerge através de relações confusas e contingentes de humanos com o restante da natureza". Adotando a perspectiva histórica de Arrighi (1994), Moore (2011a) considera que os sistemas históricos emergem por meio de sucessivas configurações da relação natureza-sociedade, e que o capitalismo é uma matriz da natureza humana e extra-humana baseada na comodificação ilimitada. Nesse sentido, a perspectiva da ecologia-mundo ilumina o que usualmente fica encoberto nos estudos ambientais, percebendo "a financeirização, industrialização, imperialismo (velho e novo) e comercialização, entre outros, como projetos socioecológicos" (MOORE, 2011a, p. 114), e a ecologia como um modo de falar "sobre as relações do todo", tratando o social e o ambiental em termos de "feixes unificados de relações distintivas" (MOORE, 2011b, p. 43).

Voltando à financeirização da natureza, Moore (2001b, p. 43) afirma que Wall Street é um modo diferente de organizar a natureza. Diferente, "mas não menos direto que a fazenda, a floresta gerenciada, ou a fábrica". A penetração do capital financeiro na reprodução da natureza humana e extra-humana representa, então, uma nova era nas relações natureza-sociedade no capitalismo.

Nesse contexto, parece bastante natural o que ocorreu no processo de preparação e de realização da Rio+20. O objetivo, como é de conhecimento público, era avaliar os progressos realizados desde a Eco-92, bem como os novos desafios a ser enfrentados. Durante o processo de preparação, os debates foram nucleados em torno das ideias promovidas pelo UNEP que, em 2008, em meio à crise financeira, lançou The Green Initiative, apelando a um novo paradigma para a retomada do crescimento:

Mobilizar e refocalizar a economia global na direção de investimentos em tecnologias limpas e na infraestrutura 'natural', tais como florestas e solos, é a melhor aposta para o crescimento real, combatendo a mudança climática e provocando um boom de empregos no século 21 (UNEP, 2008).

A Global Economy Initiative - lançada pela UNEP em 2008, no ápice das crises globais financeira e econômica - tem servido para informar os governos de duas oportunidades únicas. Primeiro, que uma fatia significativa de pacotes de estímulos de trilhões de dólares podem ser acessados se o foco em investimentos ambientais for empregado para reativar a economia global, salvar e criar empregos, e ao mesmo tempo enfrentar desafios ambientais emergentes. A segunda é que tais investimentos em conjunto com reformas políticas domésticas em áreas-chave, o desenvolvimento de políticas internacionais e de infraestrutura de mercado, podem criar o estágio para a transição para uma verdadeira "Economia Verde": uma economia que leve ao aumento da riqueza, ofereça emprego decente, enfrente desigualdades e a pobreza persistente com sucesso, e reduza a escassez ecológica e riscos climáticos. O relatório Global Green New Deal, lançado em fevereiro de 2009 , recomendou que $1 \%$ do PNB global, ou algo em torno de $1 / 3$ dos pacotes de estímulo globais, possam apoiar esta transição. [...] Organizações e forums relevantes, do G20 à OECD, tem também enfatizado o crescimento verde e a economia verde como uma importante nova direção (UNEP, 2010, p. 3).

De fato, um dos resultados do encontro do G20 realizado em Pittsburgh (EUA), em 2009, foi afirmar que uma das razões da crise havia sido a inadequada valorização da natureza (G20, 2009). Foi, portanto, sendo produzido consenso em torno desse novo paradigma - a economia verde - que se organizaria em torno de 
tecnologias limpas e da instrumentalização da infraestrutura natural, aliando crescimento efetivo, combate às mudanças climáticas e promoção do emprego (UNEP, 2009).

Essas proposições iniciais foram consubstanciadas no documento lançado em 2011 intitulado Green Economy Report. Nele se encontra a defesa de que o desenvolvimento sustentável pode ser atingido através do estabelecimento de valores monetários por serviços ambientais da natureza (serviços ecossistêmicos), expansão das compensações e da comercialização de créditos, e desenvolvimento de tecnologias limpas. As palavras-chave são mercados e tecnologia. A suposição é que seria possível assegurar a proteção da natureza com a recuperação e aceleração do crescimento econômico (UNEP, 2011).

A noção de serviços ecossistêmicos é, certamente, a expressão mais evidente da comodificação da natureza. $\mathrm{O}$ argumento é que a natureza, como qualquer prestador de serviço que atua no mercado, deve ter seus serviços medidos e avaliados de acordo com o realizado (limpeza da água, sequestro de carbono, ciclo do nitrogênio etc.). Esses serviços podem ser pagos por mecanismos de compensação ou podem ser assegurados sob a forma da criação de créditos que podem ser trocados para gerar recursos para a conservação. Ao mesmo tempo, podem ser desenvolvidas tecnologias para aumentar o valor desses serviços do ecossistema e, portanto, gerar lucros (UNEP, 2011). A expressão se originou no trabalho de biólogos conservacionistas. Em 2003, a World Wild Fund (WWF) lançou uma obra editada por Gutman, na qual está sistematizada a ideia de pagamentos pelos ecosserviços. Em uma publicação de 1997, Constanza et al. realizaram uma estimativa segundo a qual o valor global anual de serviços do ecossistema seria de US\$ 16 a 54 trilhões. Nesse trabalho os autores argumentavam que a exclusão de fatores ambientais, como as externalidades, não representava adequadamente seus impactos. No entanto, o trabalho que realizaram foi usado em outra direção, servindo para evidenciar os lucros possíveis de serem obtidos nesse novo mercado.

O fato é que quase 20 anos e centenas de Conferências e Encontros depois da Eco-92, depois de milhares de páginas de resoluções, declarações e protocolos, a situação ambiental no planeta continua se deteriorando. Em uma aparente contradição, a Rio+20 ficou marcada pelo aprofundamento e expansão da comercialização e mercantilização do ambiente natural e seus serviços, e seu principal resultado foi referendar os termos do documento The future we want (UNITED NATIONS ORGANIZATION, 2012). No contexto da crise desencadeada a partir de 2008 , crise produzida exatamente pelo modelo de acumulação vigente crescimento contínuo e crescente associado à especulação financeira - a proposição da UNEP, referendada na Rio+20, reforça esse modelo, apostando em um sistema baseado no crescimento sem limites e, para apoiar a recuperação da crise, investe ainda mais sobre a natureza.

A economia verde, conceito central do documento The future we want (UNITED NATIONS ORGANIZATION, 2012), é definida como uma "economia de baixo carbono, eficiente no uso de recursos naturais e socialmente inclusiva" (UNEP, 2011, p. 16). Na verdade, a menção ao tema da inclusão social e a referência, na chamada oficial da Rio+20, ao desenvolvimento sustentável e à erradicação da pobreza, evidenciam uma necessária concessão discursiva às ressalvas geradas, principalmente na comunidade internacional de ONGs, contra uma abordagem estritamente econômica.

Assim como ocorreu com o desenvolvimento sustentável, economia verde também é um termo vago e impreciso. Como diz Löwy (2012, p. 2), em entrevista, "ou se trata de uma economia capitalista ou de uma economia não capitalista". No caso da economia verde, "não é outra coisa do que uma economia capitalista de mercado que busca traduzir em termos de lucro e rentabilidade algumas propostas".

Em outro registro, Almeida (2012, p. 94) argumenta que, no plano teórico, a economia verde não é um novo conceito, mas a proposta de um conjunto de instrumentos e a reiteração de ideias já conhecidas na literatura sobre economia do meio ambiente. Seu argumento ajuda a compreender a expressão para além das declarações de seus formuladores. De acordo com a autora, a única novidade estaria na aproximação de abordagens da economia neoclássica e evolucionária com autores da estratégia corporativa. Nos próximos parágrafos revisaremos sinteticamente esses conteúdos e sua articulação, com base em Almeida (2012), mas, também, na consulta aos autores por ela trabalhados e com a inclusão de alguns outros. 
A primeira abordagem é da Curva Kuznets Ambiental (CKA). Seu conceito surgiu no início dos anos 1990 para descrever a relação, em nível nacional, entre crescimento econômico e poluição. A inspiração e o nome decorrem da hipótese elaborada por Kuznets (1966), segundo a qual haveria uma relação na forma de U invertido entre a medida de desigualdade na distribuição de renda e o nível de renda per capita. Aplicada ao ambiente, a suposição é que o crescimento em países pobres gera poluição, em um primeiro momento, porque o país não prioriza seu controle. Assim que o país ganhasse suficiente grau de riqueza, a prioridade mudaria para incluir a proteção ambiental. Se o efeito renda fosse forte o suficiente, haveria diminuição da poluição. Ou seja, a melhoria ambiental, nesses países, não poderia ocorrer sem crescimento econômico (GROSSMAN e KRUEGER, 1995; STERN, 1998).

A economia verde é uma proposta que visa dinamizar os efeitos composição e tecnologia para conciliar crescimento econômico com qualidade ambiental e inclusão social [...]. A mesma ideia de desacoplamento (decloupling) entre crescimento econômico e depleção de recursos naturais, degradação ambiental, que está por trás da CKA é parte essencial do argumento em favor do desenvolvimento sustentável (STERN, 1998), como também se encontra na base da economia verde. [...] Uma questão central frequentemente colocada sobre a CKA é se o desacoplamento seria uma consequência automática do crescimento econômico per se ou um processo induzido por políticas públicas. [...] Já na proposta da economia verde não há dúvida sobre o determinante em última instância do desacoplamento: trata-se de um processo induzido por políticas, sobretudo as de incentivo a inovações (ALMEIDA, 2012, p. 95).

Esse aspecto representa uma aproximação com a economia evolucionária e sua ênfase em instrumentos de regulação. O trabalho que marca a emergência dessa abordagem foi elaborado por Alchian (1950) e relacionava o processo de seleção natural com a hipótese da firma maximizadora de lucros. Desse trabalho se desdobraram duas vertentes: uma marcada pela abordagem neoclássica, representada por Friedman (1953) e incluindo o argumento da seleção para justificar a maximização; outra influenciada por Schumpeter, representada por Winter (1964) e considerando a seleção como um movimento interativo sem finalidade prédefinida que resulta em complexidade, não em perfeição.

A aproximação entre economia evolucionária e desenvolvimento sustentável se deu através da vertente inaugurada por Winter (1964) e sedimentada em trabalhos posteriores, como os de Nelson e Winter (1982), Faber e Proops (1990) e Ayres (1991). A afinidade conceitual decorre da definição de evolução como mudança. Se a sustentabilidade ambiental é considerada como um critério para o equilíbrio na relação entre ambiente e sistema econômico, a economia evolucionária estuda o processo de desequilíbrio na transição para o equilíbrio. De acordo com Faber e Proops (1990), a abordagem evolucionária presta mais atenção no longo prazo do desenvolvimento econômico do que a economia neoclássica. Além disso, ela inclui aspectos qualitativos, relativos à dimensão institucional e à mudança tecnológica (NELSON, 1995), além da consideração das leis da termodinâmica em algumas de suas formulações (AYRES, 1994).

Especificamente em relação à articulação entre economia e ambiente, na perspectiva da economia evolucionária se encontra a ênfase na instituição de mecanismos regulatórios e de incentivos ao desenvolvimento e difusão de tecnologias ambientais, necessários porque os mecanismos de preço não são suficientes para promover estímulos a esse desenvolvimento (AYRES, 1991). Ou seja, "a inovação tecnológica ambiental deve ser induzida deliberadamente por regulações e políticas apropriadas" (ALMEIDA 2012, p. 96).

A mesma ênfase é identificada por Almeida (2012) em textos daquela época produzidos por autores da estratégia corporativa, com o é o caso de Porter (1991). No que ficou conhecida como a hipótese de Porter, haveria uma relação sinérgica entre lucros privados e melhoria ambiental, que seria decorrência dos ganhos econômicos produzidos por inovações tecnológicas ambientais. 
Na mesma direção, Hart (1995) propõe uma teoria das vantagens competitivas com base na relação da firma com o ambiente natural. Essa teoria é composta por três estratégias interconectadas: prevenir a poluição, minimizar o custo do ciclo de vida dos produtos e desenvolvimento sustentável. $\mathrm{O}$ autor defende que cada uma dessas estratégias é fundamental para sustentar a vantagem competitiva. Em desenvolvimentos posteriores, é sistematizada uma abordagem win-win. Hart e Milstein (2003, p. 56) defendem que os desafios globais associados com a sustentabilidade, vistos através das "lentes adequadas dos negócios", podem contribuir para a identificação de estratégias que contribuam simultaneamente para um mundo mais sustentável e para a criação de valor para os acionistas. Essa abordagem é definida como a criação de valor sustentável para a firma e inclui quatro dimensões centrais. As três primeiras são as mesmas propostas por Hart (1995) e sintetizadas acima, a quarta é a cocriação de novos negócios para satisfazer necessidades não atendidas dos pobres.

Nessas abordagens, o desenvolvimento sustentável é definido através da ênfase, simultânea, na degradação ambiental produzida nos países do Sul Global pelo consumo realizado no Norte e pela construção de mercados no Sul com a simultânea redução do impacto ambiental. Ou seja, a estratégia de desenvolvimento sustentável resulta de uma visão de longo prazo que leva em conta o fato de que, na década seguinte, os mercados do Sul teriam o dobro do tamanho dos mercados do Norte sendo, portanto, essenciais para que as corporações ganhem vantagens na competição em mercados globais.

Mais uma vez fica evidente a evolução do desenvolvimento sustentável à economia verde, considerando a modernização ecológica como fundamento e, como fica claro na revisão acima, a adoção dos mesmos fundamentos da economia e da gestão. O que se trata, a partir das propostas da UNEP e de organizações parceiras, é de uma radicalização da investida do mercado sobre a natureza, como discutiremos nos próximos parágrafos.

A abordagem baseada no mercado assume, como já mencionado, que a natureza precisa ser precisamente mensurada e valorizada de acordo com os serviços que provê. Essa proposição vinha sendo construída já há alguns anos. Em maio de 2007, o Ministério para o Ambiente da Alemanha havia proposto, no Encontro do G8, um estudo sobre o significado da perda global da biodiversidade. Na sequência, a Alemanha e a Comissão Europeia encomendaram um estudo que ficou conhecido como The economics of ecosystems \& biodiversity (TEEB), coordenado por um funcionário sênior do Deutsche Bank - Pavan Sukhdev. Na página de abertura do sítio da TEEB (2012a) encontramos uma síntese do que a natureza faz por nós, "de graça": provê alimentos; serviços culturais através da experiência espiritual; regula eventos extremos; e provê matéria-prima.

A natureza provê a sociedade humana com uma vasta diversidade de benefícios tais como alimento, fibras, água limpa, solo fértil, captura de carbono e muito mais. Apesar de nosso bem-estar ser totalmente dependente dos fluxos contínuos desses "serviços do ecossistema", eles são predominantemente bens públicos sem mercados e sem preços, só raramente são considerados pelo seu valor econômico. Como resultado, a biodiversidade está declinando, nossos ecossistemas estão sendo continuamente degradados e nós, em decorrência, estamos sofrendo as consequências. Tomando como inspiração as ideias desenvolvidas no Millennium Ecosystem Assessment, nossa iniciativa, The Economics of Ecosystems \& Biodiversity (TEEB), tem por objetivo promover um melhor entendimento do verdadeiro valor econômico dos serviços ecossistêmicos e oferecer ferramentas econômicas para uma adequada consideração do seu valor (EUROPEAN COMMUNITIES, 2008, p. 9).

Durante a Rio+20 foi divulgado um documento preparado especialmente para o evento. Logo na apresentação fica clara importância do conceito de capital natural: 
A natureza é essencial para a saúde e crescimento das economias, sociedades e indivíduos, através da provisão de serviços ecossistêmicos [...]. A natureza também oferece uma gama de serviços culturais relacionados à saúde humana, recreação, turismo, conhecimento científico e espiritual e identidade cultural. Ao prover estes serviços às pessoas, a natureza pode ser compreendida como um ativo natural e, portanto, pode ser vista como "capital natural", existindo junto ao capital manufaturado, financeiro, social e humano (TEEB, 2012b, p. 1).

Vai, assim, consubstanciando-se a utopia do mercado total: a constituição de uma sociedade que só adota como critério de decisão a eficácia formal. Hinkelammert (2001, p. 33) alerta que "quando este critério domina sobre todos os outros valores, a relação com os valores se torna puramente nihilista": valores valem quando coincidem com as exigências da eficiência e deixam de valer quando não coincidem. Agora, a natureza adquire um novo valor, porque pode ser objetiva e eficientemente valorizada, de modo a produzir um novo ciclo de acumulação do capital:

O capital natural, junto com outras formas de capital, é insumo-chave para uma variedade de setores econômicos. É único no sentido de que provê o que é frequentemente grátis, não poluente, e com baixo teor de carbono para a produção, como água limpa para ecossistemas ou serviços de polinização pelas abelhas em apoio à produção agrícola. Ele também provê inspiração para a inovação, conhecimento científico e assegura a proteção de ativos (através de fluxos de controle) (TEEB, 2012b, p. 1).

Ao ler esse trecho, vem à mente uma imagem à semelhança daqueles desenhos animados em que os animais têm expressões e agem como se fossem seres humanos. Nessa imagem, exércitos de abelhinhas industriosas, trabalhadoras e disciplinadas, fazem parte, agora, da força de trabalho a serviço do capital (Figura 1).

\section{Figura 1}

\section{Foto ilustrativa da matéria sobre o TEEB Brasil}

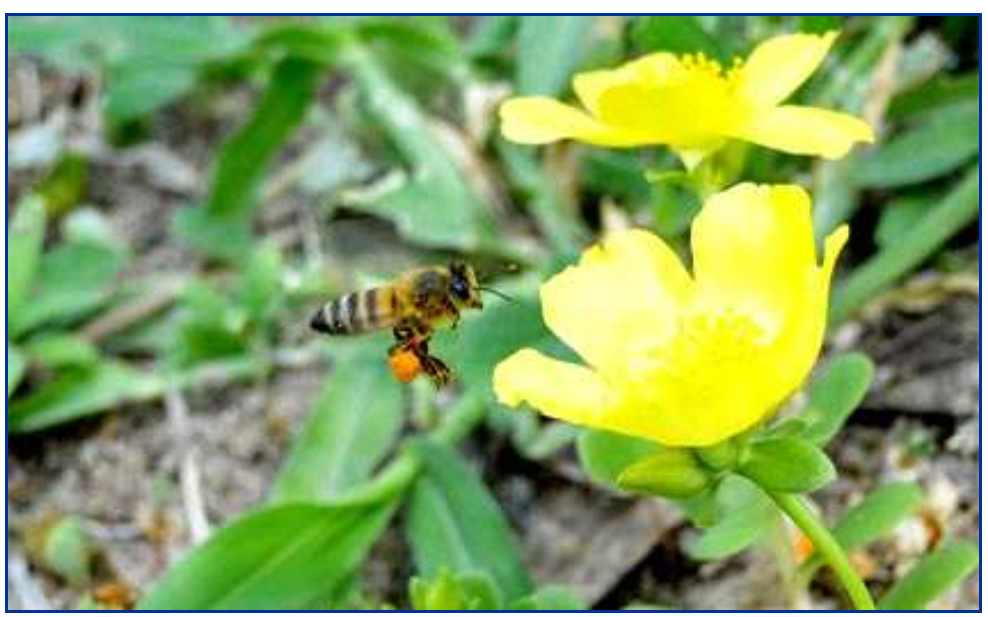

Fonte: http://www.ecodesenvolvimento.org/posts/2011/junho/especial-meio-ambiente-teeb (ECOD, 2011).

Antes da Rio+20, as proposições da economia verde já haviam sido assumidas pelo governo brasileiro. Para operacionalizar a investida sobre a natureza foi criado o TEEB Brasil, uma iniciativa conjunta do Ministério do Meio Ambiente (MMA), do Instituto de Pesquisa Econômica Aplicada (IPE), da UNEP e da Conservação Internacional do Brasil. 
De acordo com o secretário de Biodiversidade e Floresta do MMA, Bráulio Dias, o projeto TEEB Brasil tem como objetivo conduzir estudos-piloto no âmbito nacional e estadual, avaliando impactos sociais e econômicos da perda da biodiversidade e degradação dos ecossistemas, bem como as respostas da sociedade (setor público, empresarial e sociedade civil) (BRASIL, 2011, p. 1).

Os estudos no Brasil terão a participação do Ministério da Fazenda, "para que seus resultados possam mudar a elaboração das políticas públicas e as práticas com relação à biodiversidade" (BRASIL, 2011, p. 1). Na primeira reunião do grupo, o assessor especial do UNEP em Economia Verde, Pavan Sukhdev, fez uma apresentação sobre as atividades do TEEB no mundo

No setor corporativo, também já ocorreram avanços. Durante a Rio+20, em um evento da Confederação Nacional da Indústria (CNI), foi lançado o "TEEB para o Setor de Negócios Brasileiro", uma iniciativa da Conservação Internacional (CI-Brasil) com apoio do Centro de Monitoramento da Conservação Mundial (UNEP-WCMC) e patrocínio da Monsanto, Vale, Natura e Santander.

O relatório preliminar traça um panorama dos riscos e das oportunidades de negócios relacionados à biodiversidade e os serviços ecossistêmicos para seis setores específicos da economia brasileira: agricultura e papel e celulose; óleo e gás e químicos; cosméticos e farmacêuticos; mineração e construção civil; instituições financeiras; e varejo (CONSERVAÇÃO INTERNACIONAL, 2012).

A Monsanto (2012) também celebrou o lançamento do Projeto, registrando que Pavan Sukhdev parabenizou a iniciativa brasileira e destacou que o documento servirá para tirar da invisibilidade o capital natural: "O capital natural tem um potencial enorme. São US\$ 5 trilhões em serviços ecossistêmicos".

Também durante a Rio+20, vinte instituições financeiras lançaram a Declaração do Capital Natural. Líder temporária da UNEP FI, Yuki Yasui disse:

Lançando a Declaração do Capital Natural na RIO+20, nossa mensagem para a cúpula de negociadores e delegações governamentais é de que o setor financeiro está pronto para dar o próximo passo no caminho inteligente da finança sustentável, e que ele convoca os tomadores de decisão a pôr em prática as condições favoráveis para facilitar esse processo (GVCES, 2012, p. 1).

A UNEP FI é uma parceria entre a UNEP e o setor financeiro, envolvendo mais de 200 instituições, incluindo bancos, seguradoras e gestoras de fundos. Participaram também da iniciativa o Global Canopy Programme - um think-tank da área de florestação e o Centro de Estudos em Sustentabilidade (GVces) da Escola FGV-EAESP (GVCES, 2012).

Devemos aqui retornar ao tema da financeirização da natureza, em diálogo com a sistematização dos seus componentes realizada por Sullivan (2011):

- Natureza financeira - movimento de investimentos financeiros em conservação e governança ambiental é o meio mais direto. Sua existência é facilmente perceptível, dada a presença de novos fundos de investimento oferecendo produtos e serviços ligados a discursos e índices ambientais. Além disto, bancos convencionais estão incorporando ativos ambientais como garantias para empréstimos e instituições financeiras internacionais estão aumentando a participação do setor privado como parceiros de países na sustentação de seu capital natural e na monetarização de serviços ecossistêmicos. 
- Trabalhos da natureza - transforma a natureza não humana em uma empresa que precisa ter reconhecidos os serviços que realiza, sendo que o pagamento vai para as organizações que forem capazes de capturá-los. Para viabilizá-lo, é necessário desenvolver um conjunto de técnicas de avaliação econômica, bem como a produção de bases regulatórias, sendo criado um novo espaço para a produção "científica".

- Natureza bancária - a partir do conceito de capital natural, a natureza é concebida como uma conta bancária. Formas de natureza bancária, gerenciadas por banqueiros da natureza, estão emergindo como estruturas de gestão na governança ambiental. "Ao criar a natureza que o capital pode ver, em parte através da capitalização dos serviços ecossistêmicos, e em conjunto com direitos formais de propriedade, proprietários de terra podem se tornar empreendedores da natureza", podem capitalizar a partir dos "novos preços vinculados a ativos naturais associados com serviços monetarizados e, portanto, faturáveis, que ocorrem em áreas definidas de terra" (SULLIVAN, 2011, p. 23).

- Derivativos da natureza - como já ocorreu no mercado de créditos de carbono, existem proposições para a criação de derivativos da biodiversidade. Mandel, Donlan e Armstrong (2010) propõem que os governos implementem contratos modificados de derivativos para vender o risco de extinção de espécies a investidores e stakeholders. Usando como exemplo o pica-pau de penacho vermelho, os autores mostram como um programa de derivativos da biodiversidade, que tenham seu valor baseado no declínio da espécie, poderia gerar novos fundos e resultar em uma conservação custo-efetiva, alinhando os interesses dos stakeholders e criando incentivos para esforços privados de conservação. Assim, se ampliam as possibilidades para a especulação com a natureza, conectando "dinâmicas da natureza com as possibilidades associadas de produzir riqueza à influência dos investimentos financeiros em outras commodities" (SULLIVAN, 2011, p. 27).

Como ocorreu nos momentos anteriores, agora também a gestão verde se coloca como parceira nesse processo. Em artigo recente, Porter e Kramer (2011) criticam as empresas por sua visão estreita de otimização dos lucros no curto prazo, recomendando que levem em consideração o impacto negativo, para seu sucesso no longo prazo, de fatores como a depleção de recursos naturais. Outro guru dos negócios, Haque (2011), lançou seu manifesto por um novo capitalismo. O autor oferece um conjunto de prescrições na direção da vantagem construtiva. Entre elas se encontra a ideia de "crescimento inteligente", um tipo de crescimento que produz valor para todos os envolvidos. É preciso ter claro que tanto Porter e Kramer (2011), quanto Haque (2011) estão defendendo a criação de lucros a partir do reconhecimento e capitalização da interdependência entre pessoas, recursos naturais e governos, de modo a garantir o crescimento econômico continuado.

A investida do capital sobre a natureza tem levado diversos autores a considerar que estamos atravessando um novo processo de acumulação primitiva. Harvey (2006), Glassmann (2006) e De Angelis (2007), entre outros, reconhecem que, apesar de os mecanismos concretos serem diferentes daqueles analisados por Marx (1981), a lógica da acumulação permanece a mesma dos tempos do início do capitalismo: o capital precisa, continuamente, estender seus poderes buscando novos territórios, setores e domínios que ainda não tenham sido incorporados à circulação. A economia verde é uma etapa radicalizada desse processo.

Mais uma vez, como já ocorreu com o desenvolvimento sustentável, estamos diante do que Löwy (2012, p. 3) chama de "reformismo verde", um reformismo que aceita as regras do capitalismo, que busca soluções compatíveis com os interesses da rentabilidade, do lucro rápido, da competitividade no mercado e do crescimento ilimitado. $\mathrm{O}$ discurso que sintetizamos em algumas partes deste ensaio parece assumir que o capital financeiro e as corporações transnacionais que operam como agentes ativos na devastação do planeta o fazem "não porque busquem maximizar suas margens de lucro no curto prazo, mas porque não têm suficiente informação, ou porque os sinais que recebem dos marcos regulatórios dentro dos quais operam não são claros" (LANDER, 2011, p. 9). É claro que esse discurso encobre o fato de que as promessas da modernização verde do capitalismo, sem alterar seus fundamentos, favorecem o grande capital, especialmente o financeiro. 
O discurso da economia verde precisa, ainda, ocultar o fato de que sempre que o capital busca possibilidades de valorização, ele exerce poder econômico e social. O que se encontra no texto, assim como já ocorria no marco do desenvolvimento sustentável, são declarações vagas e falaciosas sobre o combate à pobreza e a geração de empregos. Não causa estranheza que os únicos instrumentos em construção sejam para avaliar os ativos ambientais e criar marcos regulatórios para transacioná-los no mercado. Também não causa estranheza a ausência de referências ao contexto social onde a monetarização da natureza ocorrerá. É como se os serviços ecossistêmicos e culturais da natureza estivessem localizados em fronteiras geográficas não exploradas. Como sabemos, não é assim. Muitos dos últimos ecossistemas preservados estão em áreas ocupadas por populações indígenas e comunidades locais nos países do Sul. Portanto, o percurso da economia verde certamente provocará mais acumulação por espoliação (HARVEY, 2006).

Compartilhando o dito popular de que uma imagem vale mais do que mil palavras, optamos por finalizar este ensaio com a reprodução de quatro variações de uma ideia muito frequente em publicações da UNEP e disponíveis em seu sítio, especialmente em boletins informativos (Figura 2). Deixamos as ideias e imagens que propusemos neste ensaio à disposição para sua reflexão e conclusões.

\section{Figura 2}

\section{Economia verde - a produção da natureza a partir e para o dinheiro}

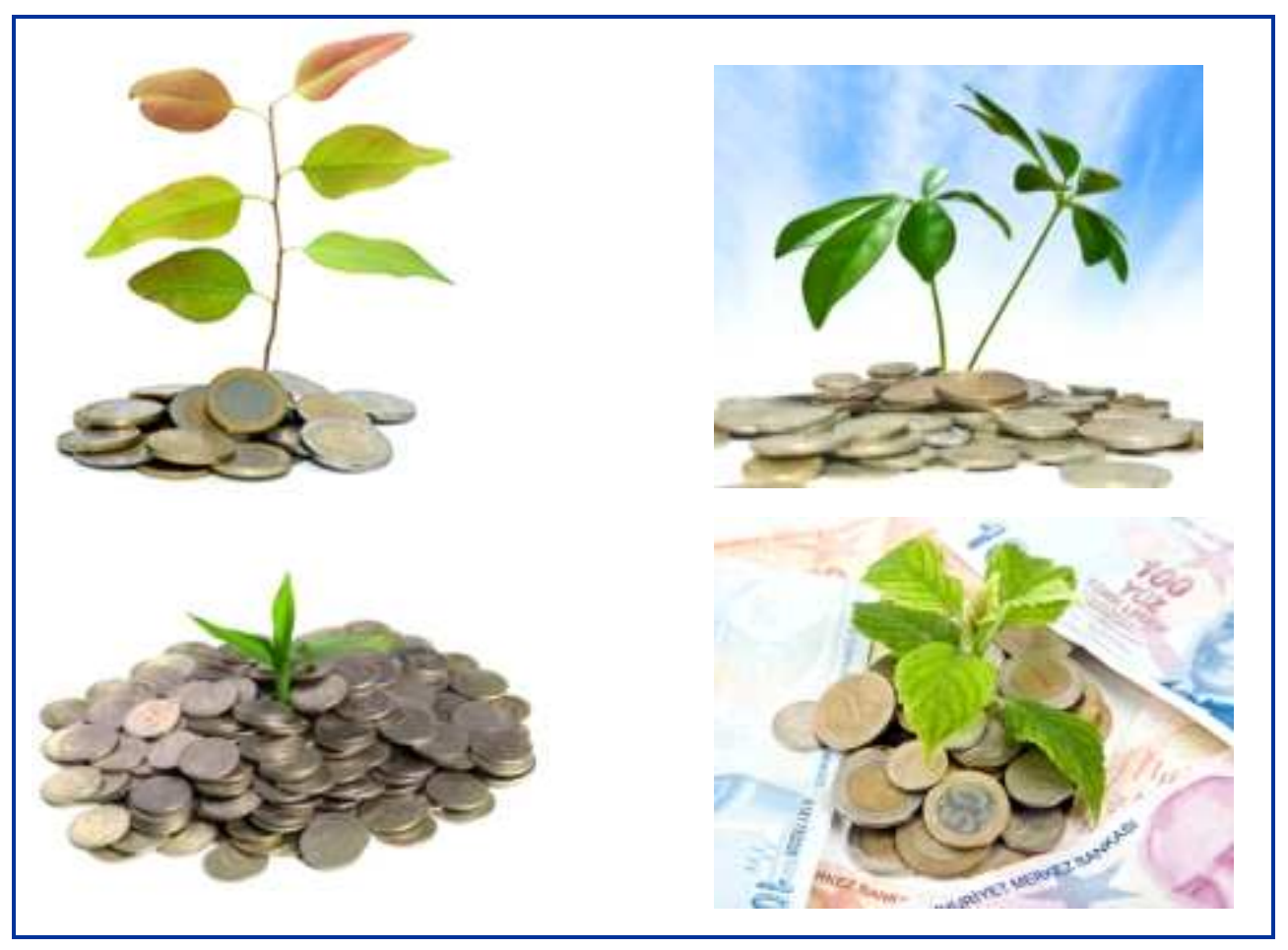

Fonte: imagens disponíveis no sítio <www.unep.org>. 


\section{Referências}

ALCHIAN, A. A. Uncertainty, evolution, and economic theory. Journal of Political Economy, n. 58, p. 211-21, 1950.

ALMEIDA, L. T. Economia verde: a reiteração de ideias à espera de ações. Estudos Avançados, v. 26, n. 74, p. 93 $103,2012$.

ARRIGHI, G. The long twentieth century: money, power and the origins of our time. London: Verso, 1994.

AYRES, R. U. Evolutionary economics and environmental imperatives. Structural Change and Economic Dynamics, n. 2, p. 255-273, 1991.

Information, entropy, and progress. New York: American Institute of Physics, 1994.

BAKHSHI, V.; KRAJESKI, A. Accounting for climate change: a window on the future. Harvard Business Review, v. 85 , n. 10, p. 36-37, 2007.

BAKKER, K. The limits of 'neoliberal natures': debating green neoliberalism. Progress in Human Geography, v. 34, n. 6 , p. 50-75, 2010.

BECKERMAN, W. Sustainable development: is it a useful concept? Environmental Values, v. 3, n. 3, p. 191-209, 1994.

BERNSTEIN, S. Liberal environmentalism and global environmental governance. Global Environmental Politics, v. 2, n. 3, p. 1-17, 2002.

BIERSTEKER, T. The 'triumph' of neoclassical economics in the developing world: policy convergence and bases of governance in the international economic order. In: ROSENAU, J. N.; CZEMPIEL, E. O. (Ed.). Governance without government: order and change in world politics. Cambridge: Cambridge University Press, 1992. p. 102-131.

BLOOMBERG NEW ENERGY FINANCE. Building bridges: state of voluntary carbon markets. 2010. Disponível em: <http://bnef.com/WhitePapers/download/28>. Acesso em: 12 jun. 2012.

BÖHM, S.; DABHI, S. (Ed.). Upsetting the offset: the political economy of carbon markets. London: Mayfly, 2009. Disponível em: <http://mayflybooks.org/?page_id=21>. Acesso em: 12 jun. 2012.

BRASIL. O valor da biodiversidade dentro das políticas públicas. 29 maio 2011. Disponível em: <http://www.mma.gov.br/informma/item/7067-o-valor-da-biodiversidade-dentro-das-politicas-publicas>. Acesso em: 14 fev. 2012.

BRUNO, K.; KARLINER, J. The UN's global compact, corporate accountability and the Johannesburg Earth Summit. Development, v. 45, n. 3, p. 33-38, 2002a.

Earthsummit.biz: the corporate takeover of sustainable development. Oakland: Food First Books, 2002b.

BUMPUS, A. G.; LIVERMANN, D. M. Accumulation by decarbonization and the governance of carbon offsets. Economic Geography, v. 84, n. 2, p. 127-155, 2008.

CENTRO DE ESTUDOS EM SUSTENTABILIDADE DA ESCOLA DE ADMINISTRAÇÃO DE EMPRESAS DA FUNDAÇÃO GETULIO VARGAS - GVCES. Vinte instituições financeiras fazem compromisso ambicioso sobre o capital natural. 4 maio 2012. Disponível em: <http://ces.fgvsp.br/index.php?r=site/conteudo\&id=203>. Acesso em: 24 jun. 2012.

CHATTERJEE, P.; FINGER, M. The earth brokers: power, politics and world development. London: Routledge, 1994. 
COHEN, B.; SMITH, B.; MITCHELL, R. Toward a sustainable conceptualization of dependent variables in entrepreneurship research. Business Strategy and the Environment, v. 17, n. 2, p. 107-119, 2008.

CONSERVAÇÃO INTERNACIONAL. TEEB para o setor de negócios brasileiro é lançado na Rio+20: Iniciativa visa a dimensionar o valor econômico da biodiversidade para o setor de negócios no Brasil e identificar oportunidades associadas ao seu uso sustentável. 15 jun. 2012. Disponível em: <http://www.conservation.org.br/noticias/noticia.php?id=608>. Acesso em: 24 jul. 2012.

CONSTANZA, R. et al. The value of the world's ecosystem services and natural capital. Nature, n. 387, p. 253-260, 1997.

CRUBELLATE, J. M.; VASCONCELOS; F. C. Gestão ambiental: uma crítica sistêmica e outras alternativas ao “otimismo verde”. Organização \& Sociedade, v. 10, n. 26, p. 91-105, 2003.

DE ANGELIS, M. The beginning of history: value struggles and global capital. London: Pluto Press, 2007.

ECOD. Especial meio ambiente: TEEB. 07/06/2011. Disponível em: <http://www.ecodesenvolvimento.org/posts/2011/junho/especial-meio-ambiente-teeb>. Acesso em: 3 set. 2012.

EUROPEAN COMMUNITIES. The economics of ecosystems \& biodiversity: an interim report. 2008. Disponível em: <http://www.unep.ch/etb/publications/TEEB/TEEB_interim_report.pdf>. Acesso em 24 jun. 2012.

FABER, M.; PROOPS, J. L. R. Evolution, time, production and the environment. New York: Springer-Verlag, 1990.

FLORINI, A. The evolution of international norms. International Studies Quarterly, v. 40, p. 363-389, 1996.

FOSTER, J. B. The absolute general law of environmental degradation under capitalism. Capitalism Nature Socialism, v. 2, n. 3, p. 77-82, 1992.

Marx’s ecology: materialism and nature. New York: Monthly Review Press, 2000.

. ; MCCHESNEY, R. Monopoly-finance capital and the paradox of accumulation. Monthly Review, New York, October 2009. Disponível em: 〈http://www.monthylyreview.org/091001foster-mcchesney.php〉. Acesso em: 13 jun. 2012.

FRIEDMAN, Milton. Essays in positive economics. Chicago: The University of Chicago Press, 1953.

G20. Leaders Statement: The Pittsburgh Summit. 24-25 set. 2009. Disponível em: <http://www.g20.utoronto.ca/2009/2009communique0925.html>. Acesso em: 12 jun. 2012.

GLADWIN, T.; KENNELLY, J.; KRAUSE, T. S. Shifting paradigms for sustainable development: implications for management theory and research. Academy of Management Review, v. 20, n. 4, p. 874-907, 1995.

GLASSMANN, J. Primitive accumulation, accumulation by dispossession, accumulation by 'extra-economic' means. Progress in Human Geography, v. 30, n. 5, p. 608-625, 2006.

GROSSMAN, G.; KRUEGER, A. Economic growth and the environment. Quarterly Journal of Economics, Oxford, v. 110 , n. 2, p. 353-377, 1995.

GUTMAN, P. (Ed.). From goodwill to payments for environmental services: a survey of financing options for sustainable natural resource management in developing countries. [S. 1.]: WWF, 2003. Disponível em: <http://portals.wi.wur.nl/files/docs/File/nfp\%20for\%20all/FinancingMech/FromGoodwilltoPESWWFcases.pdf>. Acesso em: 24 jun. 2012.

HADEN, S. S. P.; OYLER, J. D.; HUMPHREYS, J. H. Historical, practical, and theoretical perspectives on green management: an exploratory analysis. Management Decision, v. 47, n. 7, p. 1041-1055, 2009. 
HAJER, M. A. The politics of environmental discourse: ecological modernization and the policy process. Oxford: Oxford University Press, 1995.

HAQUE, U. The new Capitalist Manifesto. Boston: Harvard Business Review Press, 2011.

HART, S. L. A natural-resource-based view of the firm. Academy of Management Review, v. 20, n. 4, p. 986-1014, 1995.

. Beyond greening: strategies for a sustainable world. Harvard Business Review, v. 75, p. 66-76, 1997.

Capitalism at the crossroads: the unlimited business opportunities in solving the world's most difficult problems. New Jersey: Wharton School, 2005.

2003.

. ; MILSTEIN, M. B. Creating sustainable value. Academy of Management Executive, v. 17, n. 2, p. 56-69,

HARTWICK, E.; PEET, R. Neoliberalism and nature: the case of the WTO. The Annals of the American Academy of Political \& Social Science, v. 590, n. 1, p. 188-211, 2003.

HARVEY, D. The new imperialism. Oxford: Oxford University Press, 2003.

Spaces of global capitalism: towards a theory of uneven development. London: Verso, 2006.

HINKELAMMERT, F. El nihilism al desnudo: los tiempos de la globalización. Santiago de Chile: LOM, 2001.

HOEDEMAN, O. Rio+20 and the greenwashing of the global economy. January 2012. Disponível em: <http://www.tni.org/article/rio20-and-greenwasghing-global-economy>. Acesso em: 12 jun. 2012.

KUZNETS, S. Modern Economic Growth. New Haven, CT: Yale University Press, 1966.

LANDER, E. The green economy: the wolf in sheep's clothing. Amsterdam: Transnational Institute, 2011. Disponível em: <http://www.tni.org/report/green-economy-wolf-sheeps-clothing>. Acesso em: 24 jun. 2012.

LASH, J.; WELLINGTON, F. Competitive advantage on a warming planet. Harvard Business Review, v. 85, n. 3, p. 94-102, 2007.

LOHMANN, L. Toward a different debate in environmental accounting: the cases of carbon and cost-benefit. Accounting, Organizations and Society, v. 34, n. 3-4, p. 399-534, 2009.

LÖWY, M. Entrevista: Michael Löwy critica Rio+20 e a propaganda da economia verde. 9 abr. 2012. Disponível em: <http://www.ihu.unisinos.br/noticias/508288-michael.loewycriticario20eapropagandadaeconomiaverde>. Acesso em: 20 jun. 2012.

MANDEL, J. T.; DONLAN, C. J.; ARMSTRONG, J. A derivative approach to endangered species conservation. Frontiers in Ecology and the Environment, n. 8, p. 44-49, 2010.

MARCH, J. G.; OLSEN, J. P. The institutional dynamics of international order. International Organization, v. 52, p. 943-970, 1998.

MARCUS, A. A.; FREMETH, A. R. Green management matters regardless. Academy of Management Perspectives, v. 23, n. 3, p. 17-26, 2009.

MARX, K. Capital. London: Penguin Books, 1981. v. 3.

MENEGHeTti, F. K. O que é um ensaio-teórico? Revista de Administração Contemporânea, v. 15, n. 2, p. 320-332, 2011. 
MILNE, M. J.; KEARINS, K.; WALTON, S. Creating adventures in wonderland: the journey metaphor and environmental sustainability. Organization, v. 13, n. 6, p. 801-839, 2006.

MISOCZKY, M. C.; MORAES, J.; FLORES, R. K. Bloch, Gramsci e Paulo Freire: referências fundamentais para os atos da denúncia e do anúncio. Cad. EBAPE.BR, v. 7, p. 448-471, 2009.

MOL, A. The refinement of production: ecological modernization theory and the chemical industry. Ultrecht: International Books, 1995.

Ecological modernization and the global economy. Global Environmental Politics, v. 2, n. 2, p. 92-114, 2002.

Globalization and environmental reform: the ecological modernization of economy. Cambridge: Cambridge University Press, 2003.

MONSANTO. Relatório preliminar do TEBB é lançado na Rio+20. 15 jul. 2012. Disponível em: <http://www.monsanto.com.br/sala_imprensa/includes/template_press_release.asp?noticiaId=743344434233432333324 34423344334334347D454392164427D4641D3624D8641D17454131BB8>. Acesso em: 24 jul. 2012.

MOORE, J. W. The end of the road? Agricultural revolutions in the capitalist world-ecology. Journal of Agrarian Change, v. 10, n. 3, p. 389-413, 2010.

. Ecology, capital and the natures of our times: a theory of crisis in the capitalist world-ecology. Journal of World-System Analysis, v. 17, n. 1, p. 108-147, 2011a. 39-53, $2011 \mathrm{~b}$

Wall Street is a way of organizing nature. Upping the Anti: a Journal of Theory and Action, Online, n. 12, p.

NELSON, R. R. Recent evolutionary theorizing about economic change. Journal of Economic Literature, n. 33, p. 48-90, 1995.

. ; WINTER, S. G. An evolutionary theory of economic change. Cambridge: Harvard University Press, 1982.

NEWELL, P. The governance of energy finance: the public, the private and the hybrid. Global Policy, v. 2 , ed. Especial, p. 92-105, 2011.

Climate capitalism: global warming and the transformation of the global economy. Cambridge: Cambridge University Press, 2010.

; PATERSON, M. The politics of carbon economy. In: BOYCOFF, M. (Ed.). Climate change: a survey. London: Routledge, 2009. p. 77-95.

O'CONNOR, J. On the two contradictions of capitalism. Capitalism Nature Socialism, v. 2, n. 3, p. 107-109, 1991.

Is sustainable capitalism possible? In: O'CONNOR, M. (Ed.). Is capitalism sustainable? Political economy and the politics of ecology. New York: The Guilford Press, 1994. p. 152-175.

O'CONNOR, M. On the misadventures of capitalist nature. In: O'CONNOR, M. (Ed.). Is capitalism sustainable? Political economy and the politics of ecology. New York: The Guilford Press, 1994. p. 125-151.

PORTER, M. America's green strategy. Scientific American, v. 264, p. 168, 1991.

.; KRAMER, R. The big idea: creating shared value. Harvard Business Review, Cambridge (USA), 2011. Disponível em: <http://hbr.org/2011/01/the-big-idea-creating-shared-value/ar/pr>. Acesso em: 24 jun. 2012.

. ; REINHARDT, F. L. A strategic approach to climate. Harvard Business Review, v. 85, n. 10, p. 22-26, 2007.

PRAHALAD, C. K. The fortune at the bottom of the pyramid. New Jersey: Wharton School, 2005. 
REDCLIFT, M. Sustainable development: needs, values, rights. Environment Values, v. 2, n. 1, p. 3-20, 1993.

. Sustainable development (1987-2005): an oxymoron comes of age. Horizontes Antropológicos, v. 12, n. 25, p. 65-84, 2006.

ROMEIRO, A. R. Desenvolvimento sustentável: uma perspectiva econômico-ecológica. Estudos Avançados, v. 26, n. 74, p. 65-92, 2012.

SANCHES, C. S. Gestão ambiental proativa. Revista de Administração de Empresas, v. 40, n. 1, p. 76-87, 2000.

SAVITZ, A. W. A empresa sustentável: como a sustentabilidade pode ajudar sua empresa. Rio de Janeiro: Campus, 2007.

SCHWARTZ, P. Investing in global security. Harvard Business Review, v. 85, n. 10, p. 26-28, 2007.

SHIVA, V. Recovering the real meaning of sustainability. In: COOPER, D. E.; PALMER, J. A. (Ed.). The environment in question: ethics in global issues. London: Routledge, 1992. p. 187-193.

SIEGEL, D. Green management matters only if it yields more green: an economic/strategic perspective. Academy of Management Perspectives, v. 23, n. 3, p. 5-16, 2009.

SILVA, S. S. da; REIS, R. P.; AMÂNCIO, R. Paradigmas ambientais nos relatos de sustentabilidade de organizações do setor de energia elétrica. Revista de Administração da Mackenzie, v. 12, n. 3, p. 146-176, 2011.

SMITH, N. Uneven development: nature, capital and the production of nature. Oxford: Blackwell, 1984.

. Nature as accumulation strategy. In: PANITCH L.; LEYS, C. (Ed.). Coming to terms with nature: socialist register - 2007. New York: Monthly Review Press, 2007. p. 19-41.

SPAARGAREN, G.; MOL, A. Sociology, environment, and modernity: ecological modernization as a theory of social change. Society Natural Resources, London, v. 5, p. 323-344, 1992.

STERN, D. I. Progress on the environmental Kuznets curve? Environmental and Development Economics, v. 3, n. 2, p. 173-196, 1998.

SULLIVAN, S. Banking nature? The financialisation of environmental conservation. 2011. Disponível em: <http://openanthcoop.net/press/2011/03/11/banking-nature/\#sdfootnote25sym>. Acesso em: 24 jun. 2012.

TEEB. The economics of ecosystems \& biodiversity. Disponível em: <http://www.teebweb.org/>. Acesso em: 24 jun. 2012a.

Nature and its role in the transition to a green economy: a contribution to Rio+20. 2012b. Disponível em:

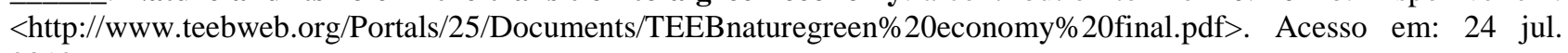
2012.

THRIFT, N. Knowing capitalism. Londres: Sage, 1995.

TIETENBERG, T. J. Emission trading: principles and practices. Washington: Resources for the Future Press, 2006.

UNITED NATIONS ENVIRONMENTAL PROGRAMME - UNEP. Global Green New Deal: an update for the G20 Pittsburgh Summit. Set. 2009. Disponível em: <http://www.unep.org/pdf/G20_policy_brief_Final.pdf〉. Acesso em: 17 jun. 2012.

Green economy report: a preview. 2010. Disponível em: <http://www.unep.org/pdf/GreenEconomyReportPreview_v2.0.pdf>. Acesso em: 17 jun. 2012. 
em:

Towards a green economy: pathways to sustainable development and poverty eradication. 2011. Disponível <http://www.unep.org/greeneconomy/Portals/88/documents/ger/ger_final_dec_2011/Green\%20EconomyReport_Final_ Dec2011.pdf $>$. Acesso em: 24 jun. 2012.

UNITED NATIONS FRAMEWORK ON CLIMATE CHANGE - UNFCC. CDM in numbers. 2011. Disponível em: <http://cdm.unfccc.int/Statistics/index.html>. Acesso em: 12 jun. 2012.

UNITED NATIONS ORGANIZATION. United Nations Conference on Sustainable Development. The future we want (outcome of the Conference). 20-22 jun. 2012. Disponível em: <http://www.uncsd2012.org/content/documents/727The\%20Future\%20We\%20Want\%2019\%20June\%201230pm.pdf>. Acesso em: 24 jun. 2012.

UNMÜßIG, B.; SACHS, W.; FATHEUER, T. Critique of the green economy: toward social and environmental equity. Berlin: Heinrich Böll Siftung, 2012.

US DEPARTMENT OF ENERGY. Greenhouse gas (GHG) offsets retail GHG offset products. 2011a. Disponível em: <http://apps3.eere.energy.gov/greenpower/markets/carbon.shtml?page=1>. Acesso em: 4 mai 2012.

Renewable energy certificates (RECs). 2011b. Disponível em: <http://apps3.eere.energy.gov/greenpower/markets/certificates.shtml?page=2\&companyid=746>. Acesso em: 4 maio 2012.

VLACHOU, A. Capitalism and ecological sustainability: the shaping of environmental policies. Review of International Political Economy, v. 11, n. 3, p. 926-952, 2004.

WINTER, S. G. Economic "natural" selection and the theory of the firm. Yale Economic Essays, v. 4, n. 1, p. 115-272, 1964.

WORLD COMMISSION ON ENVIRONMENT AND DEVELOPMENT - WCED. Our Common Future. Oxford: Oxford University Press, 1987. 